\section{THE OPERATIONAL CALCULUS}

\author{
By Prof. H. T. H. PIAGgIO
}

$\mathrm{A}^{\mathrm{T}}$ T the thirtieth meeting of the Indian Science Congress, held at Calcutta during January 2-4, Dr. S. C. Dhar, president of the Section of Mathematics and Statistics, discussed certain developments of mathematics in the last thirty years. Mathematical research is now so varied that it is difficult for an active worker in one branch to follow progress in other branches. It is, therefore, very valuable when a specialist can give an intelligible summary of the chief results obtained, in some particular subject. Dr. Dhar selected "Operational Calculus and Automorphic Functions". In what appears below, Dr. Dhar's address has been supplemented by matter obtained from other sources.

The operational calculus is associated particularly with the names of Oliver Heaviside ("Electromagnetic Theory", 1893, 1899, and 1912), T. J. I'A. Bromwich, and J. R. Carson. Heaviside's object was to solve certain problems concerning electrical eircuits, which led to a set of differential equations. Self-taught and working in isolation, he not only took no trouble to conform with recognized mathe. matical methods, but even seemed to take a delight in apparently unsound arguments. "Mathematics," he said, "is of two kinds, Rigorous and Physical. The former is Narrow : the latter Bold and Broad. To have to stop to formulate rigorous demonstrations would put a stop to most physico-mathematical enquiries. Am I to refuse to eat because I do not fully understand the mechanism of digestion ?"

This attitude aroused great opposition from the pure mathematicians. But there was something to he said on their side. (Heaviside'himself said, "even Cambridge mathematicians deserve justice".) Ever since the introduction of the differential calculus, mathematicians had been tempted to rely on intuition rather than on rigid proof. By this means they obtained speedily a large number of results, but unfortunately many of these were not altogether sccurate. The error generally consisted of the assertion as a universal truth of a theorem which actually held good only in certain conditions. Only in the later part of the nineteenth century had Weierstrass and Dedekind succeeded in abolishing the slipshod methods of the preceding two hundred years, and in returning to the high ideals of mathematical rigour held by the ancient Greeks. To those who took part in this reform, Heaviside's methods seemed a kind of mathematical blasphemy, a wilful sinning against the light. Yet Heaviside's results were always correct ! Could a tree be really corrupt if it always brought forth good fruit ?

It may be recalled that a similar situation arose early in the nineteenth century. Fourier expanded functions in an infinite series of harmonic terms, and applied the results to problems in the conduction of heat. The results were very valuable, and yet the 'rnethods by which they were obtained were unsound, as was pointed out at the time by Lagrange. The investigation of the reason for the success of Fourier's work was very difficult, but it ultimately led to great advances, and may be taken as the startingpoint of the theory of functions of a real variable. Possibly with this in mind, pure mathematicians of the twentieth century, when the battle for rigour had been won and the victors could afford to take up a more tolerant attitude, began to show more appreciation of the "Bold and Broad". Prof. G. H. Hardy, some time before 1914, expressed the view that what analysis then needed was a twentieth century Euler, capable of trying daring experiments with what one might call "conjuring tricks in mathenatics" ; the details of justification might then be filled in by workers at their leisure.

However, the task of justifying Heaviside's methods proved unexpectedly difficult. His basic idea was to treat the differential operator $p$ as an algebraical symbol, and to pass from a differential equation to a subsidiary algebraic equation which had the distinctive property of incorporating the initial conditions. The solution of this equation was resolved into partial fractions, or expanded in inverse powers of the operator, which were interpreted as integrations. Sometimes fractional powers of the operators occurred, and these were interpreted by a rule which was a natural generalization of that for integral powers. Unfortunately, as the work proceeded, more and Inore apparently arbitrary rules were needed to reach the correct result. Dr. Bromwich was the first to give any rational explanation of these rules, but he found it necessary to adopt an entirely different approach, namely, the use of complex variables and contour integrals, a method first used for differential equations by Cauchy. A German, K. W. Wagner, independently studied the problem at the same time (1916) and obtained some of Bromwich's results. Since then operational methods have been generally accepted, although there is still some doubt concerning their application to partial differential equations. Bromwich considered that Heaviside must be ranked with the greatest constructive mathematicians of the nineteenth century, far outstripping the finest senior wranglers of the Mathematical Tripos in his amazing skill in manipulation.

Another justification of Heaviside's work was given in 1917 by an American, J. R. Carson, using only the real variable. By means of the equation

$$
\phi(p)=p \int_{0}^{\infty} e^{-p t} f(t) d t,
$$

he set up a correspondence between $f(t)$, a given function of the time, and its operational representation or symbolic image $\phi(p)$. From this Carson derived a set of theorems of the utmost importance in operational calculus and in the solution of electrical problems. Further developments are due to many writers, in particular Van der Pol (from 1929). A recent book is Carslaw and Jaeger's "Operational Methods in Applied Mathematics" (1941). Besides the primary application to differential equations, operational methods give a simple method of obtaining relations between functions by finding the much simpler relations which often hold between the symbolic images and then transforming the results.

Dr. Dhar also dealt, but more briefly, with automorphic functions, which may be defined as functions which remain invariant when subjected to a group of bilinear transformations. Automorphic functions are a generalization of trigonometric functions, which are periodic, and of elliptic functions, which are doubly periodic. The pioneer work was due to Poincaré (1881) and Klein (1882). Recent advances have been due to E. T. Whittaker and his pupils. 